\title{
MORTALIDADE POR CÂNCER BUCAL, EM SANTA CATARINA
}

\begin{abstract}
Marcelo Aldrighi Moreira Mestrando em Saúde Coletiva, Universidade do Extremo Sul Catarinense, marmoreira22@hotmail.com

Beatriz Elibio Fagundes Cirurgião Dentista, Universidade do Extremo Sul Catarinense, beatrizefagundes@hotmail.com
\end{abstract} Abigail Lopes Mestranda em Saúde Coletiva, Universidade do Extremo Sul Catarinense, nutri. abigail@gmail.com Fabrício Gonçalves de Oliveira Mestrando em Saúde Coletiva, Universidade do Extremo Sul Catarinense, fabricio-fisio@hotmail.com Luciane Bisognin Ceretta Doutora, Universidade do Extremo Sul Catarinense, luk@unesc.net Renan Antônio Ceretta Doutor, Universidade do Extremo Sul Catarinense, rce@unesc.net

Priscyla Waleska Simóes Doutora, Universidade do Extremo Sul Catarinense, pri@unesc.net

\section{RESUMO}

O câncer oral é atualmente considerado um grave problema de saúde pública mundial. A Organização Mundial da Saúde estimou que, globalmente, no ano 2030, pode-se esperar 27 milhões de novos casos de câncer, bem como 
17 milhóes de mortes por câncer e 75 milhóes de pessoas vivas, anualmente, com câncer. A previsão é que os países de baixa e de média renda sofram maior impacto ocasionado por esse aumento. O câncer na cavidade oral representa $3 \%$ a $5 \%$ do total de cânceres, sendo mais frequente a neoplasia de cabeça e de pescoço. A epidemiologia do câncer da boca é assunto bem documentado na literatura, e as diferenças regionais de incidência ao redor do mundo parecem estar relacionadas aos dois principais fatores de risco: tabagismo e ingestão de bebidas alcoólicas. Uma das estratégias mais eficientes para diminuir a taxa de mortalidade do câncer de cavidade oral é controlar os fatores de risco, que, sabidamente, levam ao desenvolvimento dessa doença. Para isso, é necessário que haja o diagnóstico precoce, possibilitando tratamentos mais eficazes e aumento da sobrevida das pessoas diagnosticadas com essa neoplasia. Ao saber disso, o objetivo deste estudo foi analisar a taxa de mortalidade por câncer bucal, no estado de Santa Catarina, no período de 1996 a 2014. Para isso, foi realizado um estudo ecológico, descritivo e temporal, com dados do Instituto Brasileiro de Geografia Estatística e do Sistema de Informaçóes sobre Mortalidade, ambos disponíveis na página do Departamento de Informática do Sistema Único de Saúde (DATASUS) e da Secretaria de Estado da Saúde de Santa Catarina. Calculou-se a taxa por meio da divisão dos óbitos por câncer bucal pela população residente no mesmo local e período, multiplicado por 100.000. Durante o período de 1996 a 2014, ocorreram 2.293 óbitos de câncer bucal no estado de Santa Catarina, com aumento progressivo das taxas até 2004 e algumas oscilaçóes nos anos posteriores. $\mathrm{O}$ estudo observou maior taxa de mortalidade no sexo masculino, obtendo uma média de 84,80 óbitos/100.000 habitantes. Quanto ao estado civil, apresentou uma porcentagem baixa (de 8,54\%) em indivíduos separados judicialmente. A macrorregião que apresentou maior coeficiente médio de óbitos por câncer bucal foi o Planalto Norte (3,18 óbitos/100.000 habitantes) e a menor, a região Nordeste (1,59 óbitos/100.000 habitantes), taxa considerada menor que a estadual (2,06 óbitos/100.000 habitantes). O perfil predominante foi composto por homens casados, de raça branca, residentes no Planalto Norte, com mais de 80 anos e baixo grau de instrução. Ressalta-se que os presentes dados foram obtidos por meio de Sistemas de Informação, podendo existir falhas nos registros, principalmente devido à subnotificação. Por se tratar de um estudo ecológico, futuras pesquisas devem investigar as estatísticas apresentadas neste trabalho.

Palavras-chave: Câncer Bucal; Epidemiologia; Fatores de Risco. 